The voltage-gated $\mathrm{Ca}_{v} \mathrm{Ca}^{2+}$ channel subunit $\alpha_{2} \delta-4$ is required for locomotor behavior and sensorimotor gating in mice

Annette Klomp1,2,3, Ryotaro Omichi4,5,", Yoichiro Iwasa, ${ }^{4,5,{ }^{* *}}$ Richard J. Smith ${ }^{2,3,4,5}$, Yuriy M.

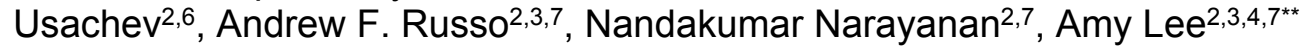

Interdisciplinary Graduate Program in Neuroscience ${ }^{1}$, lowa Neuroscience Institute ${ }^{2}$, Department of Molecular Physiology and Biophysics ${ }^{3}$, Department of Otolaryngology-Head and Neck Surgery, ${ }^{4}$ lowa Institute of Human Genetics ${ }^{5}$, Department of Neuroscience and Pharmacology ${ }^{6}$, Department of Neurology ${ }^{7}$, University of lowa, lowa City, lowa, 52242

*Present address: Department of Otolaryngology-Head and Neck Surgery, Okayama University Graduate School of Medicine, Dentistry and Pharmaceutical Sciences, Okayama 7008558, Japan.

${ }^{* *}$ Present address: Department of Otorhinolaryngology, Shinshu University School of Medicine, Matsumoto 390-8621, Japan.

${ }^{* * *}$ Present address: Dept. of Neuroscience, University of Texas-Austin, Austin, TX, 78712

Abbreviated title: $\alpha_{2} \delta-4$ and motor and sensorimotor function

${ }^{*}$ Corresponding author:

Amy Lee

Dept. of Neuroscience

University of Texas-Austin

100 E. $24^{\text {th }}$ St.

Austin, TX 78712

\title{
Email: amy.lee1@austin.utexas.edu
}

Keywords: calcium, schizophrenia, L-type channel, depression, bipolar disorder 


\begin{abstract}
Voltage-gated $\mathrm{Ca}_{\mathrm{v}} \mathrm{Ca}^{2+}$ channels are critical for the development and mature function of the nervous system. Variants in the CACNA2D4 gene encoding the $\alpha_{2} \delta-4$ auxiliary subunit of these channels are associated with neuropsychiatric and neurodevelopmental disorders. $\alpha_{2} \delta-4$ is prominently expressed in the retina and is crucial for vision, but extra-retinal functions of $\alpha_{2} \delta-4$ have not been investigated. Here, we sought to fill this gap by analyzing the behavioral phenotypes of $\alpha_{2} \delta-4$ knockout (KO) mice. $\alpha_{2} \delta-4 \mathrm{KO}$ mice (both males and females) exhibited significant impairments in prepulse inhibition that were unlikely to result from the modestly elevated auditory brainstem response thresholds. Whereas $\alpha_{2} \delta-4 \mathrm{KO}$ mice of both sexes were hyperactive in various assays, only females showed impaired motor learning/coordination in the rotarod assay. Female but not male $\alpha_{2} \delta-4 \mathrm{KO}$ mice exhibited anxiolytic and anti-depressive behaviors in the elevated plus maze and tail suspension tests, respectively. Our results reveal an unexpected role for $\alpha_{2} \delta-4$ in cognitive and motor function and identify $\alpha_{2} \delta-4$ KO mice as a novel model for studying the pathophysiology associated with CACNA2D4 variants.
\end{abstract}




\section{Introduction}

Voltage-gated $\mathrm{Ca}_{v} \mathrm{Ca}^{2+}$ channels mediate $\mathrm{Ca}^{2+}$ signals that initiate a vast array of signaling events including gene transcription, protein phosphorylation, and neurotransmitter release. The main properties of these channels are determined by a pore-forming $\alpha_{1}$ subunit, while auxiliary $\beta$ and $\alpha_{2} \delta$ subunits regulate the trafficking and some functional aspects of these channels (1). These subunits are encoded by four genes each (2), with additional functional diversity conferred by extensive alternative splicing (3). The physiological importance of $\mathrm{Ca}_{\mathrm{v}}$ channels is reflected in the numerous diseases that linked to mutations in the genes encoding the $\mathrm{Ca}_{\mathrm{v}}$ subunits which include migraine, ataxia, and disorders of vision and hearing $(4,5)$.

In recent years, variants in $\mathrm{Ca}_{v}$ encoding genes have been consistently identified in genome-wide association studies of neuropsychiatric disorders. One of the most prominent of such studies analyzed single-nucleotide polymorphisms (SNPs) in 60,000 individuals and uncovered $C A C N A 1 C$, the gene encoding $\mathrm{Ca}_{v} 1.2$, as a major risk gene for schizophrenia, bipolar disorder, major depressive disorder, autism spectrum disorder, and attention deficit hyperactivity disorder (ADHD). Pathway analysis further revealed an association of other $\mathrm{Ca}_{\mathrm{v}}$-encoding genes with these disorders, including CACNA2D4 that encodes the $\alpha_{2} \delta-4$ subunit (6). This result was rather unexpected given that $\alpha_{2} \delta-4$ was thought to be expressed primarily in the retina, where it associates with the $\mathrm{Ca}_{v} 1.4$ channel and regulates the structure and function of photoreceptor synapses (7-9).

$\alpha_{2} \delta$ is an extracellular protein that regulates the cell-surface trafficking of $\mathrm{Ca}_{\mathrm{v}}$ channels (10), but may have additional roles. For example, $\alpha_{2} \delta-1$ binding to thromobospondins promotes synapse formation in a manner that is inhibited by the analgesic and anti-convulsant drug, gabapentin (11). At the Drosophila neuromuscular junction, $\alpha_{2} \delta-3$ is required for proper synapse morphogenesis-a process that does not involve its association with the $\mathrm{Ca}_{v} 2.1$ channel (12). In the retina, the formation of photoreceptor synapses involves the role of $\alpha_{2} \delta-4$ as a $\mathrm{Ca}_{v} 1.4$ subunit 
and as a mediator of trans-synaptic interactions of the cell adhesion molecule, ELFN-1, with postsynaptic glutamate receptors (9).

Despite the association of $\alpha_{2} \delta-4$ with neuropsychiatric disease, how $\alpha_{2} \delta-4$ contributes to cognitive and affective functions is unknown. To address this question, we examined the behavioral phenotypes of $\alpha_{2} \delta-4$ knockout (KO) mice (8).

\section{Materials and Methods}

Animals

All procedures using animals were approved by the University of lowa Institutional Animal Care and Use Committee. The $\alpha_{2} \delta-4 \mathrm{KO}$ mouse line was bred on a C57/BI6 background and characterized previously (8). Separate cohorts of males (15-25 week old, $n=10$ wild-type (WT), $\mathrm{n}=11 \mathrm{KO})$ and females $(11-22$ week old, $n=11 \mathrm{WT}, \mathrm{n}=11 \mathrm{KO})$ were analyzed. Before beginning handling and testing, mice were ear punched for identification. All mice were housed in groups of 2-3 animals per cage for the duration of the handling and testing periods with food and water ad libitum (describe details of the cages). The room in which the mice were housed was maintained on a consistent light cycle with lights on at 0900 and lights off at 2100 and testing took place between 0800 to 1300 . Males and females were tested in separate cohorts at different time points to prevent pheromones on the testing apparatus from impacting results. Mice were generally acclimatized for $30 \mathrm{~min}$ in the room in which the assay was conducted prior to initiating the test. A full week was taken between every test to reduce the impact of stress from previous tests on the next result. The order of testing was designed to minimize the impact of preceding assays by performing those with the least stressful tasks first. 


\section{Auditory Brainstem Responses}

Auditory brainstem responses (ABRs) were performed as described previously (13). Mice were anesthetized with intraperitoneal injection of ketamine $(100 \mathrm{mg} / \mathrm{kg})$ and xylazine $(10 \mathrm{mg} / \mathrm{kg})$. Recordings were conducted on both ears of all animals on a heating pad using electrodes placed subcutaneously in the vertex and underneath the left or right ear. Clicks were square pulses $100 \mathrm{~ms}$ in duration, and tone bursts were $3 \mathrm{~ms}$ in length at distinct 8-, 16-, and $32 \mathrm{kHz}$ frequencies. ABRs were measured using BioSigRZ software (Tucker-Davis Technologies), with stimulus levels adjusted in 5-dB increments between 25 and 100 dB SPLs in both ears. Electrical signals were averaged over 512 repetitions and ABR threshold was defined as the lowest sound level at which a reproducible waveform was measured.

\section{Elevated Plus Maze}

The testing apparatus consisted of a plus-shaped maze elevated $40 \mathrm{~cm}$ above the floor. Two opposing closed and open arms extended from a central zone. Open arms had no walls whereas closed arms were surrounded by gray walls. The floor of the maze was made of gray plastic material. Illumination intensity in the central square was approximately 500 lux. Mice were moved from the home cage to the central square of the maze, always facing the same closed arm. The animals were allowed to explore the maze for $10 \mathrm{~min}$. In the event of a fall, the animal was placed in the central square facing the same closed arm and recording resumed. Time spent in the open and closed arms was evaluated using video recording and Anymaze software.

\section{Light Dark Box}

The testing apparatus consisted of a chamber divided into a light and dark compartment equipped with infrared beam tracking (Med Associates). The apparatus was divided into 2 chambers with a gap in the wall between them. Mice were tested using a very bright light in the light chamber (27,000 lux). Mice were moved from the home cage to the light side of the apparatus facing away 
from the dark chamber. The animals were allowed to freely explore and move between the chambers for 30 min and the animals' movements were documented in sequential 5 min intervals via infra-red tracking. Time spent in either compartment was analyzed by Activity Monitor software.

\section{Open Field Test}

The testing apparatus consisted of an open square chamber with walls of $40 \mathrm{~cm}$ height and width. Illumination intensity in the central square was approximately 500 lux. Mice were moved from the home cage to the center of the open chamber. The animals were allowed to freely explore the chamber for 10 minutes. Animal behavior was evaluated using video recording and Anymaze software. Relative time spent in the inner and outer portion of the box were taken as a measure of the animals' anxiety-like behavior. Total distance traveled over the 10 minutes was taken as a measure of the animals' basal activity level.

\section{Prepulse Inhibition}

The testing apparatus consisted of a startle response box (SR-LAB from San Diego Instruments). A restraint chamber consisted of a clear plastic tube from which the tremble response of the animal could be measured via an accelerometer underneath the chamber. Animals were placed in the restraint chamber and allowed to acclimate to the chamber for 10 min with a consistent background white noise level of $65 \mathrm{~dB}$ which was present for the entire experiment. The 25-min testing period was divided into 3 blocks each consisting of 6 or 60 trials. All trials were presented with a randomly spaced intertrial interval ranging from 7 to 15 seconds. The first block consisted of 6 pulse trials at $120 \mathrm{~dB}$. The second block contained 12 of each of the following trial types: standard pulse at $120 \mathrm{~dB}$, no stimulation, prepulse of $+4 \mathrm{~dB}$ above background, prepulse of +8 $\mathrm{dB}$, and prepulse of $+16 \mathrm{~dB}$. The third block consisted of 6 pulse trials at $120 \mathrm{~dB}$. Startle response 
amplitudes (in $\mathrm{mV}$ ) were measured in SR-LAB software and \%PPI measured as (startle response for pulse alone - startle response for pulse with pre-pulse) / startle response for pulse alone) $\mathrm{X}$ 100.

\section{Rotarod Test}

The testing apparatus consisted of a rotating spindle $3.0 \mathrm{~cm}$ in diameter that will increase in speed over the course of the trial (Rotamex 5). Mice were trained for 2 consecutive days with 3 testing trials per mouse each day separated by at least $30 \mathrm{~min}$. For the testing trial, the speed of rotation was increased by $1.2 \mathrm{rpm}$ every $20 \mathrm{~s}$ and the latency to fall was recorded. The 6 testing trials were averaged for each mouse.

\section{Forced Swim Test}

The testing apparatus consisted of a 2-liter beaker filled with $1200 \mathrm{ml}$ of water at room temperature. Mice were placed in the water and monitored for $6 \mathrm{~min}$, then were dried and placed in a recovery cage with a cage warmer. Time spent immobile was recorded, with immobility defined as lack of motion in the hind legs except necessary movement to balance and keep the head above the water.

\section{Tail Suspension Test}

The testing apparatus consisted of a metal bar suspended $30-40 \mathrm{~cm}$ above the table. Tails of the mice were wrapped in adhesive tape within the last $1 \mathrm{~cm}$ of the tail. A clear plastic tube was placed around the animal's tail to prevent climbing up the tail and onto the bar. Time spent immobile was recorded, with immobility defined as lack of attempting to move their limbs as described previously (14). 


\section{Statistics}

Statistical analysis was done with GraphPad Prism software 8.0 and RStudio. An alpha level of 0.05 was used for all statistical tests. For datasets without repeated measures, data were first tested for normality by the Shapiro-Wilk test and homogeneity by Levene's test. For parametric data, ANOVA with post hoc Holm-Sidak's multiple comparisons test was performed. For nonparametric data, Kruskal Wallis tests were used with post hoc Dunn's multiple comparisons. For data sets with repeated measures, a repeated measures linear mixed model was used with post hoc estimated marginal means. The main effects were reported if there was no significant interaction, and post hoc analysis was performed on the main effects that had more than two levels. Otherwise, post hoc tests were performed and simple main effects were reported using adjusted $p$ value for multiple comparisons. Data were graphically represented as mean \pm standard

error of the mean (SEM) for each group. Results were considered significant when $p<0.05$ (denoted in all graphs as follows: ${ }^{*} p<0.05 ;{ }^{* *} p<0.01$; ${ }^{* * *} p<0.001$ ).

\section{Results and Discussion}

$\alpha_{2} \delta-4 \mathrm{KO}$ mice were born at normal Mendelian ratios and did not exhibit any overt behavioral phenotypes other than hyperactivity. The control wild-type (WT) strain corresponded to C57BI6 strain on which the $\alpha_{2} \delta-4 \mathrm{KO}$ mice were bred for at least 10 generations. Cohorts of male and female mice were analyzed separately, and there were no differences in body weight of the WT and $\alpha_{2} \delta-4 \mathrm{KO}$ mice used in this study (Table 1). 
Table 1: Body weights $(\mathrm{g})$ of animal subjects in this study

\begin{tabular}{|r|r|r|r|r|}
\hline Cohort: & WT F & WT M & KO F & KO M \\
\hline & 22 & 26.1 & 24.4 & 31.1 \\
\hline & 23.4 & 25.1 & 22.1 & 28.7 \\
\hline & 20.7 & 27.5 & 21.5 & 29.4 \\
\hline & 19.9 & 35.1 & 27.8 & 33 \\
\hline & 23.4 & 30.4 & 26.6 & 29.9 \\
\hline & 21.3 & 32.9 & 22 & 27.6 \\
\hline & 22.8 & 33.1 & 20.7 & 31.6 \\
\hline & 24 & 28.4 & 20.4 & 27 \\
\hline & 22 & 29.2 & 20.7 & 30.9 \\
\hline & 18.5 & 27.7 & 21.7 & 25.8 \\
\hline Mean & 21.636 & $\mathbf{2 9 . 5 5}$ & $\mathbf{2 2 . 5 1 8}$ & $\mathbf{2 9 . 2 8 2}$ \\
\hline StDev & $\mathbf{1 . 6 4 9 9}$ & $\mathbf{3 . 1 0 0 4}$ & $\mathbf{2 . 4 9 9 8}$ & $\mathbf{2 . 1 4 8 5}$ \\
\hline
\end{tabular}

Animals $(n=43)$ were weighed prior to any of the behavioral tests in this study. There was no significant effect of genotype on body weight in cohorts of females $\left(\mathbf{F} ; F_{9,10}=2.103, p=\right.$ $0.6857)$ or males $\left(\mathbf{M} ; F_{1,39}=7.876, p=0.8277\right)$.

Prepulse inhibition is impaired in $\alpha_{2} \underline{\delta}-4 \mathrm{KO}$ mice. Sensorimotor gating is a form of pre-attentive processing that is commonly studied in humans and animals using prepulse inhibition (PPI). In this test, a response to a strong acoustic stimulus is generally diminished when it is preceded by a subthreshold stimulus (15). Reductions in PPI are thought to reflect impairments in working memory in individuals diagnosed with schizophrenia, bipolar disorder, and post-traumatic stress disorder and in animal models of these conditions $(16,17)$. Because of the association of $\mathrm{Ca}_{\mathrm{v}^{-}}$ encoding genes with these disorders (6), we tested whether $\alpha_{2} \delta-4 \mathrm{KO}$ mice exhibit deficits in PPI. WT and $\alpha_{2} \delta-4 \mathrm{KO}$ were tested for startle responses to a $120 \mathrm{~dB}$ acoustic stimulus that was administered alone or after a prepulse stimulus of 4,8 , or $16 \mathrm{~dB}$, and PPI was expressed as the $\%$ change in the response amplitude due to the prepulse (\%PPI, Fig.1A,B). In this assay, there was a significant main effect of both $\operatorname{sex}\left(F_{1,39}=7.876, p<0.01\right)$ and genotype $\left(F_{1,39}=10.26, p<\right.$ $0.01)$, but no interaction between these variables $\left(F_{1,39}=0.0028, p=0.958\right.$; Fig.1B). PPI was significantly lower for $\alpha_{2} \delta-4$ KO than for WT mice in the cohort of females $(p<0.05$ for both 8 and $16 \mathrm{~dB}$ prepulse) and males ( $p<0.05$ for $8 \mathrm{~dB}, p<0.01$ for $16 \mathrm{~dB}$ prepulse). In some mouse 
strains, relatively low levels of PPI correlate with low basal startle amplitudes (17). However, basal startle amplitudes were significantly higher in $\alpha_{2} \delta-4 \mathrm{KO}$ mice than in WT mice $\left(F_{1,39}=55.50, p<\right.$ 0.001; Fig.1C). Some studies have shown that patients with schizophrenia have an impaired habituation to the startle pulse (18), which would manifest as a difference in startle response to the $120 \mathrm{~dB}$-stimulus administered without the prepulse (blocks 1-3, Fig.1A). There was no effect of genotype on this parameter $\left(F_{2,78}=1.580, p=0.213\right)$. Collectively, these results show that $\alpha_{2} \delta-4$ KO mice exhibit impaired PPI without alterations in habituation.

Figure 1. $\alpha_{2} \delta-4$ KO mice exhibit impaired PPI. (A), Schematic of PPI session design. Block $1 \&$ 3 each consist of 6 test pulses $(120 \mathrm{~dB})$ alone trials. In block 2, animals were exposed to a period of no stimulation, the test pulse alone, or test pulses preceded by a PPI prepulse of 4 , 8 , or 12 $\mathrm{dB}$. Each trial type (total of 12) was presented in a randomized order with varying intertrial interval. Each test pulse was $40 \mathrm{~ms}$ and prepulse was $20 \mathrm{~ms}$ in duration. (B) \%PPI evoked by the indicated prepulse intensities. (C) Startle response amplitudes evoked by test pulses without prepulses. * $p$ $<0.05 ;{ }^{* *} p<0.01 ;{ }^{* * *} p<0.001$ by linear mixed model.

In the retina and cochlea, $\alpha_{2} \delta$ proteins support the activity of $\mathrm{Ca}_{v} 1.4$ and $\mathrm{Ca}_{\mathrm{v}} 1.3$ channels that mediate glutamate release at the specialized ribbon synapse of photoreceptors and inner hair cells, respectively (19). Although detailed analyses of $\alpha_{2} \delta$ variants in the cochlea are lacking, $\alpha_{2} \delta-4$ has been detected in cochlear hair cells by single cell RNA sequencing (20). To determine whether hearing impairment could contribute to weakened PPI in $\alpha_{2} \delta-4 \mathrm{KO}$ mice, we measured auditory brain stem responses (ABRs). In this assay, elevated ABR thresholds correlate with hearing deficits. In response to click stimuli, $\alpha_{2} \delta-4 \mathrm{KO}$ males had significantly higher thresholds than WT males $(p<0.05)$. For pure tone stimuli from $8 \mathrm{kHz}$ to $32 \mathrm{kHz}$, there was no overall effect of genotype or $\operatorname{sex}\left(F_{1,60}=1.0140, p=0.318 \& F_{1,60}=2.3092, p=0.134\right)$, but an interaction 
between genotype and $\operatorname{sex}\left(F_{1,60}=8.0533, p<0.01\right)$ indicated lower thresholds in $\alpha_{2} \delta-4 \mathrm{KO}$ females than in WT females ( $p<0.01$, Fig.2). Nevertheless, all $\alpha_{2} \delta-4$ KO mice displayed functional hearing above $60 \mathrm{~dB}$, the range used in the PPI assays, which argues against the possibility that the reduced PPI of the $\alpha_{2} \delta-4 \mathrm{KO}$ mice resulted from hearing loss.

Figure 2. $\alpha_{2} \delta-4 \mathrm{KO}$ mice exhibit sex-specific alterations in ABRs. Thresholds (dB) were plotted for WT and $\alpha_{2} \delta-4 \mathrm{KO}$ mice in response to click and pure tone stimuli of the indicated frequencies. ${ }^{*} p<0.05 ;{ }^{* *} p<0.01 ;{ }^{* * *} p<0.001$ by Kruskal-Wallis, Dunn's test, linear mixed model, and estimated marginal means.

$\underline{\alpha}_{2} \underline{\delta}-4 \mathrm{KO}$ mice exhibit anxiolytic and antidepressant phenotypes. Anxiety and depression are common features of a variety of neuropsychiatric disorders, including those associated with CACNA1C variants (21) and have a high rate of comorbidity with schizophrenia (22, 23), ADHD (24), ASD (25), bipolar disorder $(23,26)$, and major depressive disorder $(23,27)$. Therefore, we tested the performance of $\alpha_{2} \delta-4 \mathrm{KO}$ mice in behavioral assays designed to assess anxiety (open field test, OFT; elevated plus maze, EPM; and light dark box, LD) and depression (forced swim test, FST; and tail suspension test, TST). In the OFT, the animals are placed in the center of an open chamber and the time spent avoiding the center is used as a metric for anxiety-like behavior (i.e., thigmotaxis). In the EPM, the animals are placed in the center of a raised platform with open and closed arms and the time spent avoiding the open arms is taken as an indicator of anxietylike behavior. While $\alpha_{2} \delta-4 \mathrm{KO}$ and WT mice did not differ in thigmotaxis in the OFT ( $p=0.99$, Fig.3A,B), $\alpha_{2} \delta-4 \mathrm{KO}$ mice spent more time in the open arms of the EPM than WT mice (Open $\eta^{2}$ $=0.141, p<0.01$ by Kruskal-Wallis; Closed $F_{1,34}=14.206, p<0.001$ by linear mixed model; Fig.3C,D). It is unlikely that visual impairment of the $\alpha_{2} \delta-4 \mathrm{KO}$ mice influenced their abilities to respond to the aversive stimuli of the OFT and EPM since these mice have normal vision in 
daylight but not dim light conditions (8). As a further test, we performed the light dark box assay in which avoidance of a chamber with a bright light stimulus is taken as a measure of anxiety-like behavior. The $\alpha_{2} \delta-4 \mathrm{KO}$ spent more time in the lighted chamber than WT mice $\left(\eta^{2}=0.100, p<\right.$ 0.05 by Kruskal-Wallis; Fig.3E,F). The light intensity used in the lighted chamber was 27,000 lux, which is well above the visual threshold for $\alpha_{2} \delta-4 \mathrm{KO}$ mice (8). Taken together, results from the EPM and LD assays support an anxiolytic phenotype in $\alpha_{2} \delta-4 \mathrm{KO}$ mice.

Figure 3. $\alpha_{2} \delta-4 \mathrm{KO}$ mice exhibit diminished anxiety-like behaviors. For WT and $\alpha_{2} \delta-4 \mathrm{KO}$ mice, graphs show the \% total time spent in the inner and outer regions of the chamber in the open field test (OFT) (A,B), open and closed arms of the elevated plus maze (EPM) (C,D), and light and dark chambers in the light-dark assay (LD) (E,F). ${ }^{*} p<0.05 ;{ }^{* *} p<0.01$; ${ }^{* * *} p<0.001$ by Kruskal-Wallis and linear mixed model.

In the TST and FST, depressive phenotypes are measured as the duration of immobility following suspension of the animal by its tail, or placement of the animal in a beaker of water, respectively. While there were no differences between genotypes in the FST, $\alpha_{2} \delta-4$ KO mice spent significantly less time immobile than WT mice in the TST $\left(F_{3,252}=15.04, p<0.001\right.$; Fig.4AF). These results indicate a task-specific antidepressant- like phenotype in the $\alpha_{2} \delta-4 \mathrm{KO}$ mice.

Figure 4. $\alpha_{2} \delta-4 \mathrm{KO}$ mice exhibit diminished depression-like behavior in the tail suspension test. For WT and $\alpha_{2} \delta-4 \mathrm{KO}$ mice, the duration spent immobile in the tail suspension test (TST) (A-C) and forced swim test (FST, (D-F) was plotted against time (in 1-min bins) during the assay. A and D represent results for males and females combined while B,C,E,F show data disaggregated by sex. Smooth line represents exponential fits of the results. ${ }^{*} p<0.05 ;{ }^{* *} p<0.01$; ${ }^{* * *} p<0.001$ by nonlinear regression. 


\section{$\underline{\alpha_{2}} \underline{\delta}-4 \mathrm{KO}$ mice exhibit abnormal motor behavior}

Abnormal motor behaviors are a common feature of neurodevelopmental disorders including ASD and ADHD (28-30). Thereofre, we tested motor function of $\alpha_{2} \delta-4 \mathrm{KO}$ mice in the rotarod assay. In this assay, the mice are placed on a rotating cylinder that is gradually accelerated and the length of time the animal can stay on the cylinder is taken as a measure of balance, coordination, and motor planning (31). The latency to fall was shorter for $\alpha_{2} \delta-4 \mathrm{KO}$ than for WT mice $\left(F_{1,39}=6.457, p<0.05\right.$; Fig.5A). To further assess motor phenotypes in the $\alpha_{2} \delta-4$ KO mice, we analyzed data in the OFT, EPM, and LD assays for aberrant locomotion. In each case, the total distance traveled by $\alpha_{2} \delta-4 \mathrm{KO}$ (both males and females) mice was significantly greater than for WT mice (OFT $\eta^{2}=0.266, p<0.001$; EPM: $F_{1,34}=16.09, p<0.001$; LD: $\eta^{2}=$ $0.490, p<0.001$; Fig.5B-D). These results show that $\alpha_{2} \delta-4 \mathrm{KO}$ mice exhibit signs of hyperactivity and sex-dependent impairment in motor coordination.

Figure 5. $\alpha_{2} \delta-4 \mathrm{KO}$ mice exhibit alterations in motor behavior. For WT and $\alpha_{2} \delta-4 \mathrm{KO}$ mice, graphs show the latency to fall in the rotarod assay (A) and total distance traveled in the OFT (B), EPM (C), and LD (D) assays. Rotarod: Genotype $F_{1,39}=6.457, p<0.05$; Sex $F_{1,39}=22.543, p<$ 0.001; Genotype:Sex $F_{1,39}=1.806, p=0.1867$ by one-way ANOVA. ${ }^{*} p<0.05 ;{ }^{* *} p<0.01 ;{ }^{* * *} p<$ 0.001 by Kruskal-Wallis and one-way ANOVA.

Our results show that $\alpha_{2} \delta-4 \mathrm{KO}$ mice exhibit a pattern of cognitive, affective, and motor behaviors that resemble those in neuropsychiatric disorders that are linked to variants in $\mathrm{Ca}_{\mathrm{v}}{ }^{-}$ encoding genes (6). Because $\alpha_{2} \delta$ proteins enhance the cell-surface trafficking of $\mathrm{Ca}_{\vee}$ channels (5), the phenotypes of $\alpha_{2} \delta-4 \mathrm{KO}$ mice could result from loss-of function of $\mathrm{Ca}_{\vee}$ channels in key brain regions such as the hippocampus, cerebral cortex, and cerebellum. A caveat is that 
compared to other $\alpha_{2} \delta$ subunits, $\alpha_{2} \delta-4$ is nearly undetectable in these brain regions (32). Moreover, mice lacking the expression of the major $\mathrm{Ca}_{\mathrm{v}}$ subtype implicated in neuropsychiatric/neurodevelopmental disorders (i.e., Ca $\mathrm{Ca}_{\sqrt{ }} 1.2$ ) exhibit increased anxiety-like behavior $\alpha_{2} \delta-4 \mathrm{KO}$ mice (33) whereas $\alpha_{2} \delta-4 \mathrm{KO}$ mice present with an anxiolytic phenotype in the EPM and LD assays (Fig.3C-F). However, deletion of $\mathrm{Ca}_{\vee} 1.2$ in the prefrontal cortex causes antidepressant behavior in the TST (34), similar to that of $\alpha_{2} \delta-4 \mathrm{KO}$ mice in our study (Fig.4A-C). $\alpha_{2} \delta-4$ could be expressed in a small subset of neurons implicated in these behaviors, thus escaping detection by quantitative PCR in homogenates of specific brain regions (32). Alternatively, $\alpha_{2} \delta-4$ could undergo pathological upregulation. For example, $\alpha_{2} \delta-4$ expression is increased in hippocampus of humans and mice following epileptic seizures (35). Given that $\alpha_{2} \delta$ proteins regulate synapse formation in part through trans-synaptic interactions with proteins other than $\mathrm{Ca}_{v}$ channels $(9,11,12,36)$, aberrant expression of $\alpha_{2} \delta-4$ could cause defects in neuronal connectivity that modify cognitive/affective behaviors.

Although blind under dim-light conditions, $\alpha_{2} \delta-4 \mathrm{KO}$ mice are expected to have normal vision under the lighting conditions used in our study $(8,9)$. To date, alterations in cognitive and/or affective function in individuals diagnosed with CACNA2D4-related vision impairment have not been reported. However, the etiology of most neuropsychiatric disorders is complex and likely involves hundreds to thousands of risk alleles distributed across the genome (37). Our findings that $\alpha_{2} \delta-4 \mathrm{KO}$ mice exhibit defects in PPI, motor function, and anxiety/depression-related behaviors validate the importance of $C A C N A 2 D 4$ as one such risk allele and that studies of the extra-retinal functions of $\alpha_{2} \delta-4$ warrant further study.

\section{Acknowledgements}

The authors thank Jussara Hagen for expert technical assistance, Anjali Rajadhyaksha and Charlotte Bavley for helpful input on analysis of behavioral studies. 


\section{References}

1. Simms BA, Zamponi GW. Neuronal voltage-gated calcium channels: structure, function, and dysfunction. Neuron. 2014;82(1):24-45.

2. Ertel EA, Campbell KP, Harpold MM, Hofmann F, Mori Y, Perez-Reyes E, et al. Nomenclature of voltage-gated calcium channels. Neuron. 2000;25(3):533-5.

3. Lipscombe D, Allen SE, Toro CP. Control of neuronal voltage-gated calcium ion channels from RNA to protein. Trends Neurosci. 2013;36(10):598-609.

4. Striessnig J. Voltage-Gated $\mathrm{Ca}(2+)-C h a n n e l$ alpha1-Subunit de novo Missense Mutations:

Gain or Loss of Function - Implications for Potential Therapies. Front Synaptic Neurosci. 2021;13:634760.

5. Dolphin AC. Voltage-gated calcium channels and their auxiliary subunits: physiology and pathophysiology and pharmacology. J Physiol. 2016;594:5369-90.

6. Cross-Disorder Group of the Psychiatric Genomics C, Genetic Risk Outcome of Psychosis C. Identification of risk loci with shared effects on five major psychiatric disorders: a genome-wide analysis. Lancet. 2013;381(9875):1371-9.

7. Lee A, Wang S, Williams B, Hagen J, Scheetz TE, Haeseleer F. Characterization of Cav1.4 complexes $\left(\alpha_{1} 1.4, \beta_{2}\right.$, and $\left.\alpha_{2} \delta-4\right)$ in HEK293T cells and in the retina. J Biol Chem. 2015;290(3):1505-21. 
8. Kerov V, Laird JG, Joiner ML, Knecht S, Soh D, Hagen J, et al. alpha2delta-4 Is Required for the Molecular and Structural Organization of Rod and Cone Photoreceptor Synapses. J Neurosci. 2018;38(27):6145-60.

9. Wang Y, Fehlhaber KE, Sarria I, Cao Y, Ingram NT, Guerrero-Given D, et al. The Auxiliary Calcium Channel Subunit alpha2delta4 Is Required for Axonal Elaboration, Synaptic Transmission, and Wiring of Rod Photoreceptors. Neuron. 2017;93(6):1359-74 e6.

10. Dolphin AC. The $\alpha 2 \delta$ subunits of voltage-gated calcium channels. Biochim Biophys Acta. 2013;1828(7):1541-9.

11. Eroglu C, Allen NJ, Susman MW, O'Rourke NA, Park CY, Ozkan E, et al. Gabapentin receptor $\alpha 2 \delta-1$ is a neuronal thrombospondin receptor responsible for excitatory CNS synaptogenesis. Cell. 2009;139(2):380-92.

12. Kurshan PT, Oztan A, Schwarz TL. Presynaptic $\alpha 2 \delta-3$ is required for synaptic morphogenesis independent of its $\mathrm{Ca}^{2+}$-channel functions. Nat Neurosci. 2009;12(11):1415-23.

13. Yoshimura H SS, Ranum PT, Moteki H, Smith RJH. . Targeted Allele Suppression Prevents Progressive Hearing Loss in the Mature Murine Model of Human TMC1 Deafness. Mol Ther. 2019;27:681-90.

14. Can A, Dao DT, Terrillion CE, Piantadosi SC, Bhat S, Gould TD. The tail suspension test. J Vis Exp. 2012(59):e3769.

15. Swerdlow NR, Weber M, Qu Y, Light GA, Braff DL. Realistic expectations of prepulse inhibition in translational models for schizophrenia research. Psychopharmacology (Berl). 2008;199(3):331-88. 
16. Braff D, Stone C, Callaway E, Geyer M, Glick I, Bali L. Prestimulus effects on human startle reflex in normals and schizophrenics. Psychophysiology. 1978;15(4):339-43.

17. Shoji $H$, Miyakawa T. Relationships between the acoustic startle response and prepulse inhibition in C57BL/6J mice: a large-scale meta-analytic study. Mol Brain. 2018;11(1):42.

18. Hammer TB, Oranje B, Fagerlund B, Bro H, Glenthoj BY. Stability of prepulse inhibition and habituation of the startle reflex in schizophrenia: a 6-year follow-up study of initially antipsychotic-naive, first-episode schizophrenia patients. Int $\mathrm{J}$ Neuropsychopharmacol. $2011 ; 14(7): 913-25$.

19. Dolphin AC, Lee A. Presynaptic calcium channels: specialized control of synaptic neurotransmitter release. Nat Rev Neurosci. 2020.

20. Liu H, Chen L, Giffen KP, Stringham ST, Li Y, Judge PD, et al. Cell-Specific Transcriptome Analysis Shows That Adult Pillar and Deiters' Cells Express Genes Encoding Machinery for Specializations of Cochlear Hair Cells. Front Mol Neurosci. 2018;11:356.

21. Kabir ZD, Lee AS, Rajadhyaksha AM. L-type $\mathrm{Ca}(2+)$ channels in mood, cognition and addiction: integrating human and rodent studies with a focus on behavioural endophenotypes. $\mathrm{J}$ Physiol. 2016;594(20):5823-37.

22. Braga RJ, Reynolds GP, Siris SG. Anxiety comorbidity in schizophrenia. Psychiatry Res. 2013;210(1):1-7.

23. Goghari VM, Harrow M. Anxiety symptoms across twenty-years in schizoaffective disorder, bipolar disorder, and major depressive disorder. Psychiatry Res. 2019;275:310-4.

24. Reimherr FW, Marchant BK, Gift TE, Steans TA. ADHD and Anxiety: Clinical Significance and Treatment Implications. Curr Psychiatry Rep. 2017;19(12):109. 
25. Simonoff E, Pickles A, Charman T, Chandler S, Loucas T, Baird G. Psychiatric disorders in children with autism spectrum disorders: prevalence, comorbidity, and associated factors in a population-derived sample. J Am Acad Child Adolesc Psychiatry. 2008;47(8):921-9.

26. Jensen RN, Csillag C, Vinberg M. [Anxiety in patients with bipolar affective disorder]. Ugeskr Laeger. 2021;183(22).

27. Tiller JW. Depression and anxiety. Med J Aust. 2013;199(S6):S28-31.

28. Manjiviona J, Prior M. Comparison of Asperger syndrome and high-functioning autistic children on a test of motor impairment. J Autism Dev Disord. 1995;25(1):23-39.

29. Green D, Charman T, Pickles A, Chandler S, Loucas T, Simonoff E, et al. Impairment in movement skills of children with autistic spectrum disorders. Dev Med Child Neurol. 2009;51(4):311-6.

30. Lense MD, Ladanyi E, Rabinowitch TC, Trainor L, Gordon R. Rhythm and timing as vulnerabilities in neurodevelopmental disorders. Philos Trans R Soc Lond B Biol Sci. 2021;376(1835):20200327.

31. Shiotsuki H YK, Shimo Y, Funayama M, Takamatsu Y, Ikeda K, Takahashi R, Kitazawa S, Hattori N. A rotarod test for evaluation of motor skill learning. J Neurosci Methods. 2010;189:180-5.

32. Schlick B, Flucher BE, Obermair GJ. Voltage-activated calcium channel expression profiles in mouse brain and cultured hippocampal neurons. Neuroscience. 2010;167(3):786-98.

33. Lee AS, Ra S, Rajadhyaksha AM, Britt JK, De Jesus-Cortes H, Gonzales KL, et al. Forebrain elimination of cacna1c mediates anxiety-like behavior in mice. Mol Psychiatry. 2012;17(11):1054-5. 
34. Kabir ZD, Lee AS, Burgdorf CE, Fischer DK, Rajadhyaksha AM, Mok E, et al. Cacna1c in the Prefrontal Cortex Regulates Depression-Related Behaviors via REDD1. Neuropsychopharmacology. 2017;42(10):2032-42.

35. van Loo KMJ, Rummel CK, Pitsch J, Muller JA, Bikbaev AF, Martinez-Chavez E, et al. Calcium Channel Subunit alpha2delta4 Is Regulated by Early Growth Response 1 and Facilitates Epileptogenesis. J Neurosci. 2019;39(17):3175-87.

36. Geisler S, Schopf CL, Stanika R, Kalb M, Campiglio M, Repetto D, et al. Presynaptic alpha2delta-2 Calcium Channel Subunits Regulate Postsynaptic GABAA Receptor Abundance and Axonal Wiring. J Neurosci. 2019;39(14):2581-605.

37. Rees E, Owen MJ. Translating insights from neuropsychiatric genetics and genomics for precision psychiatry. Genome Med. 2020;12(1):43. 
A

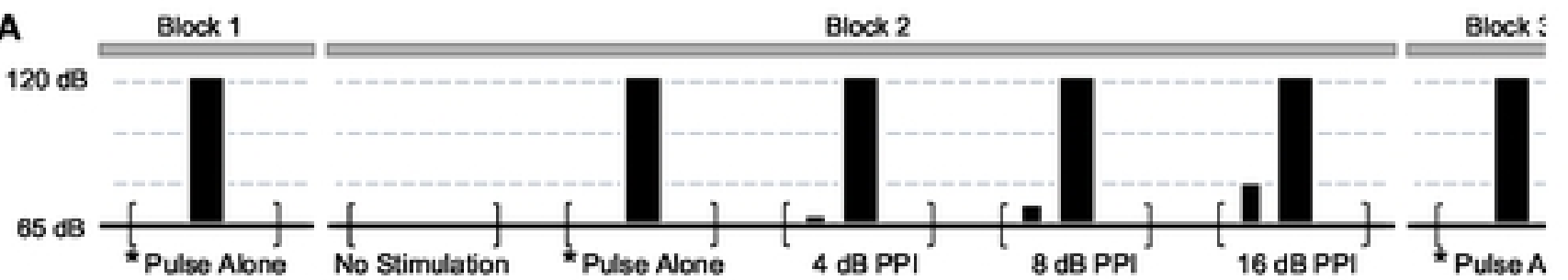

B

C
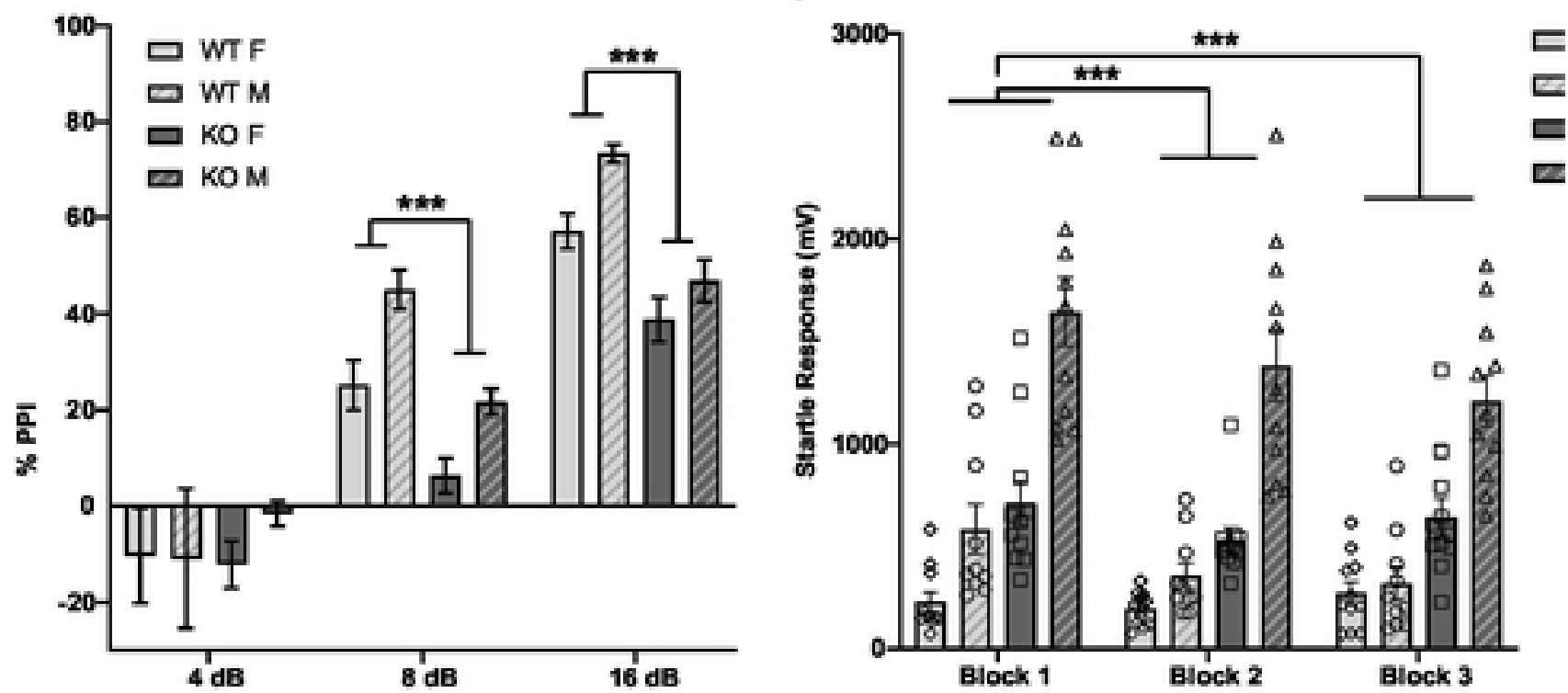

Figure 1 
Figure 2

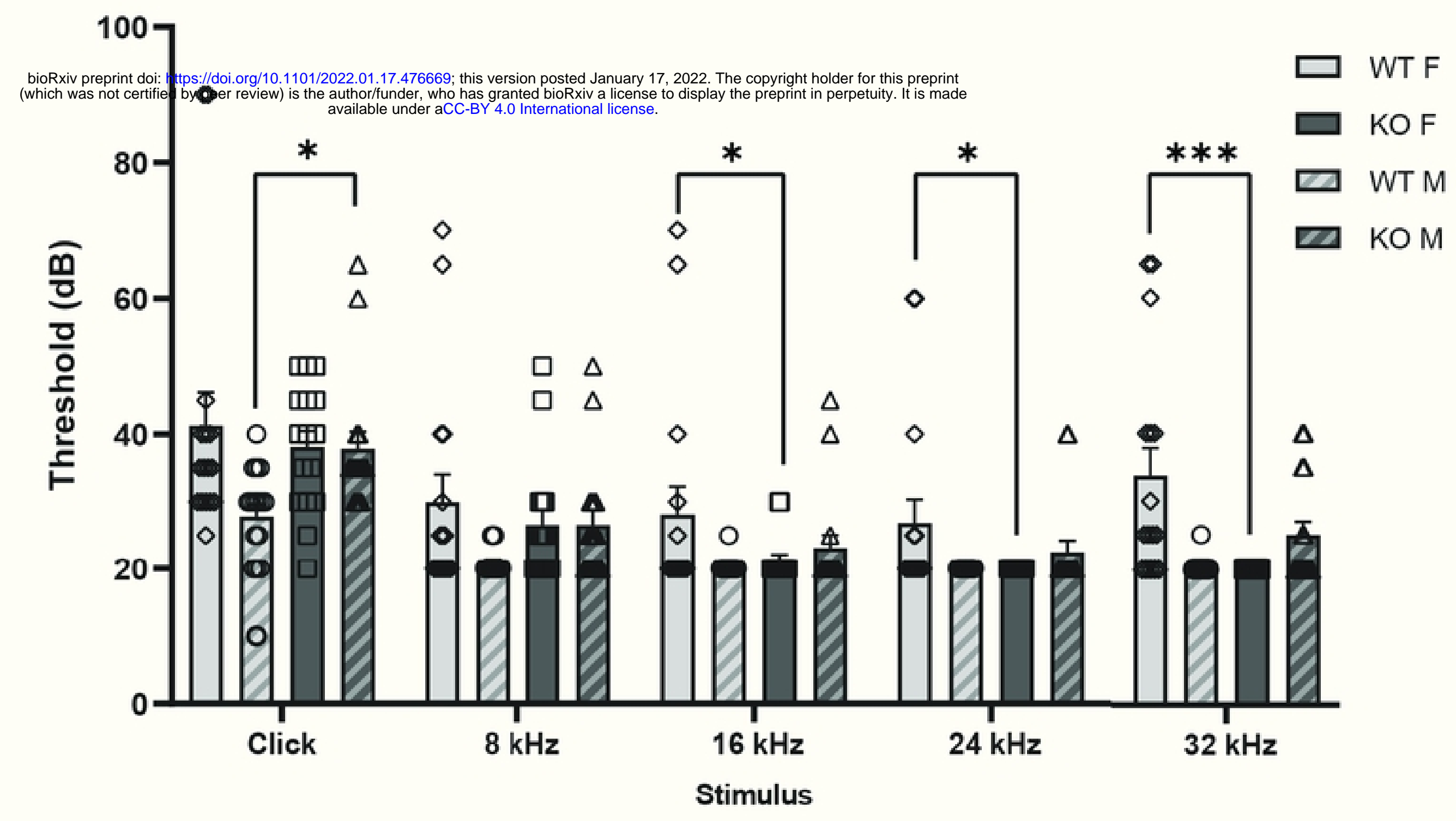

Figure 2 
Figure 3

A

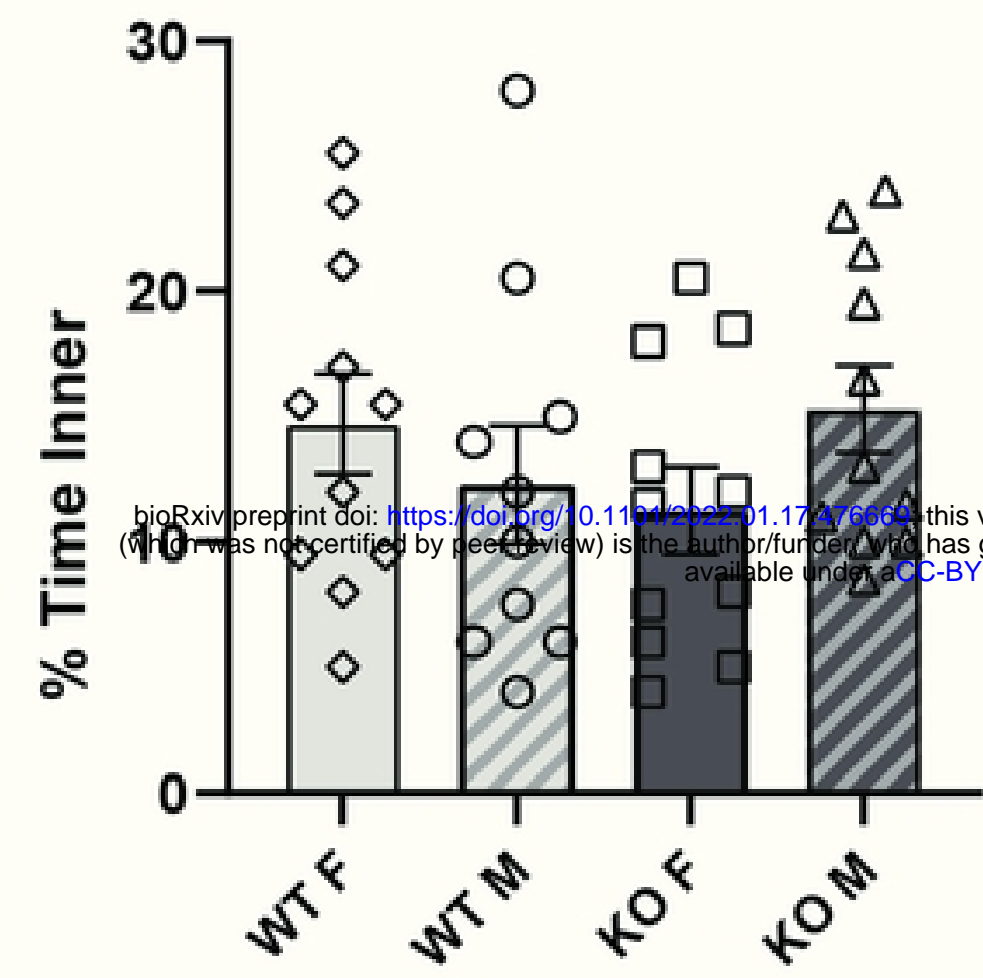

B

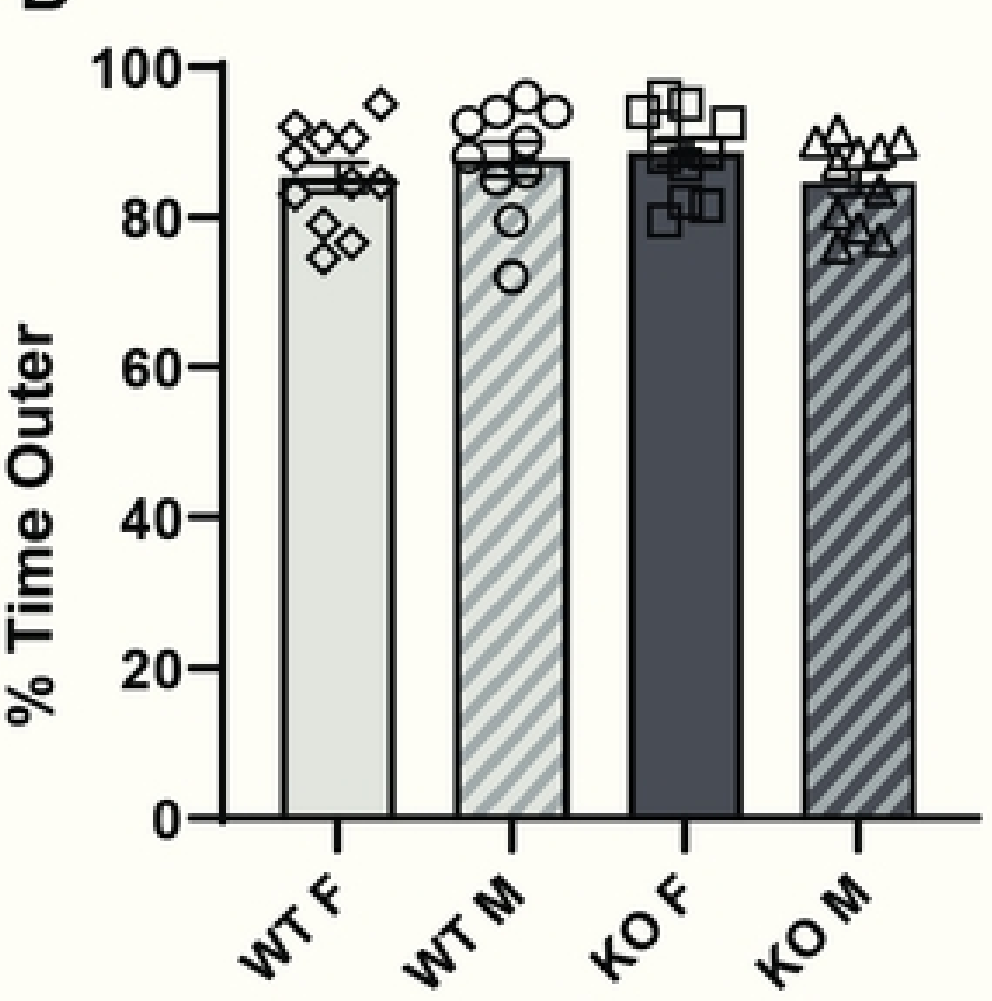

C

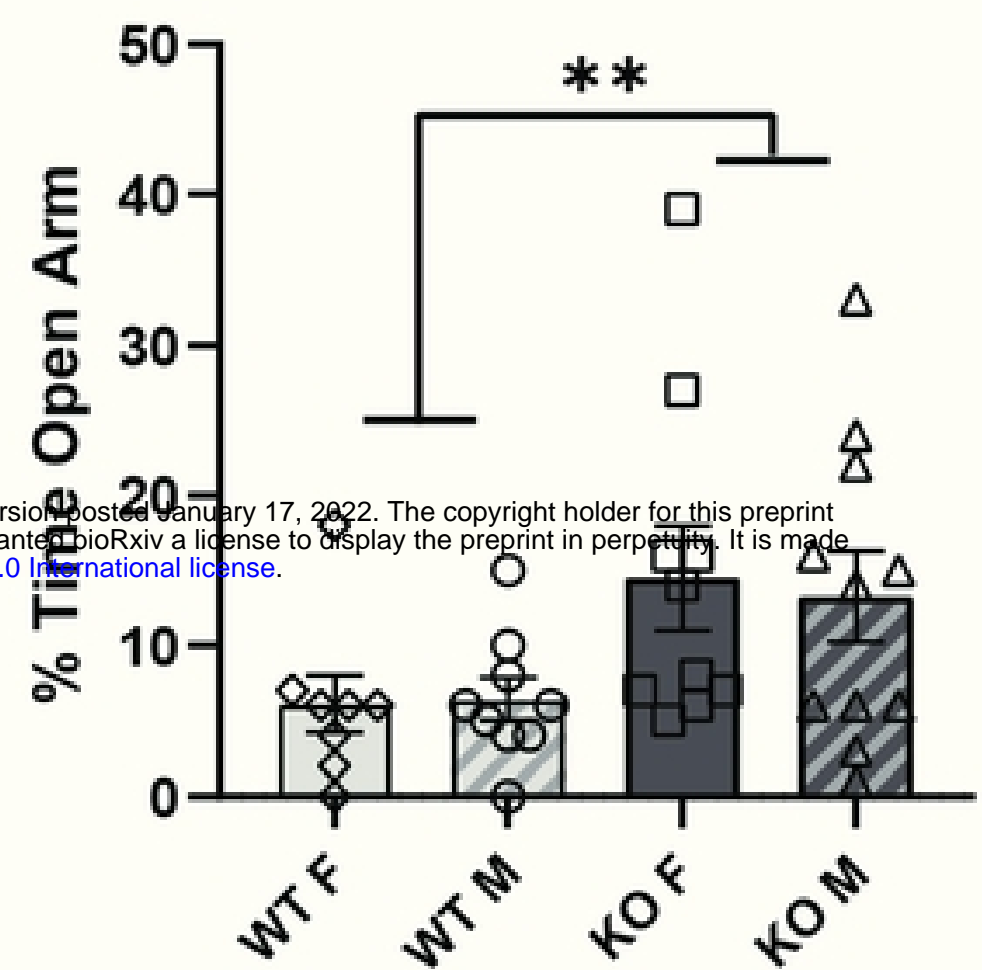

D

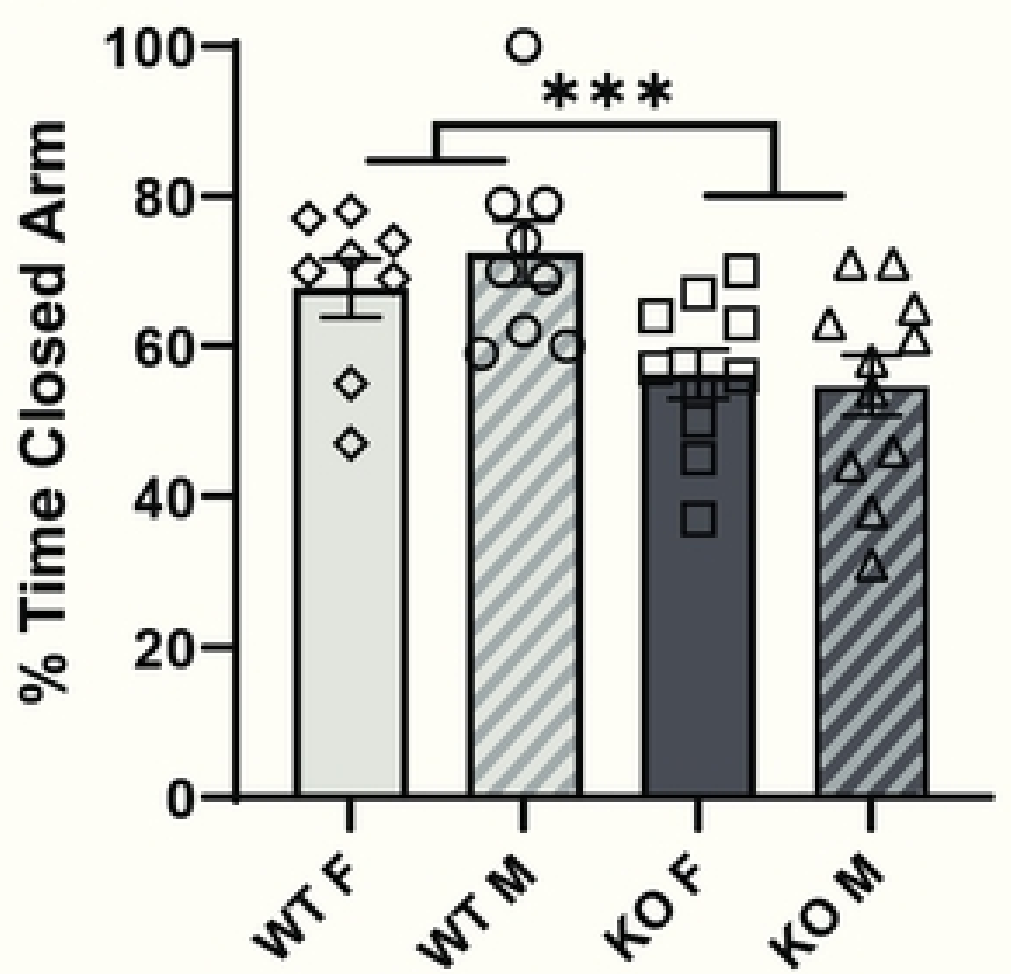

E

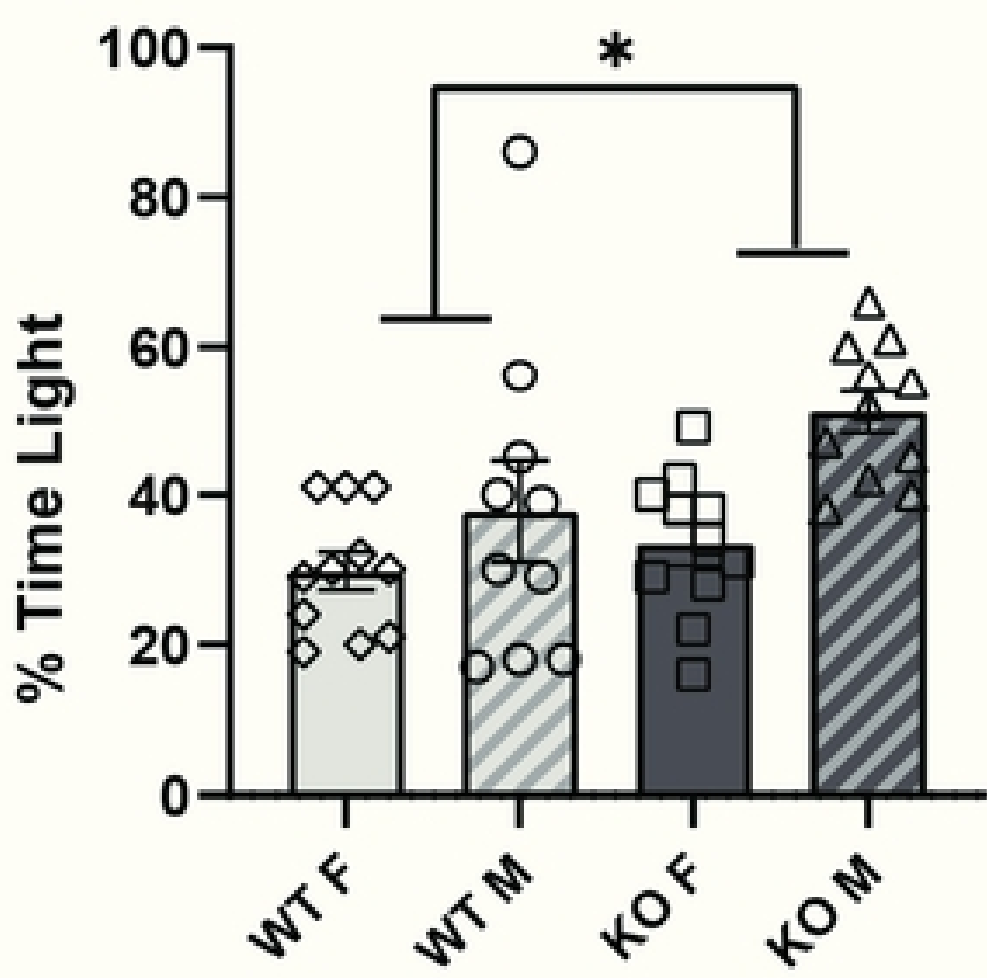

F

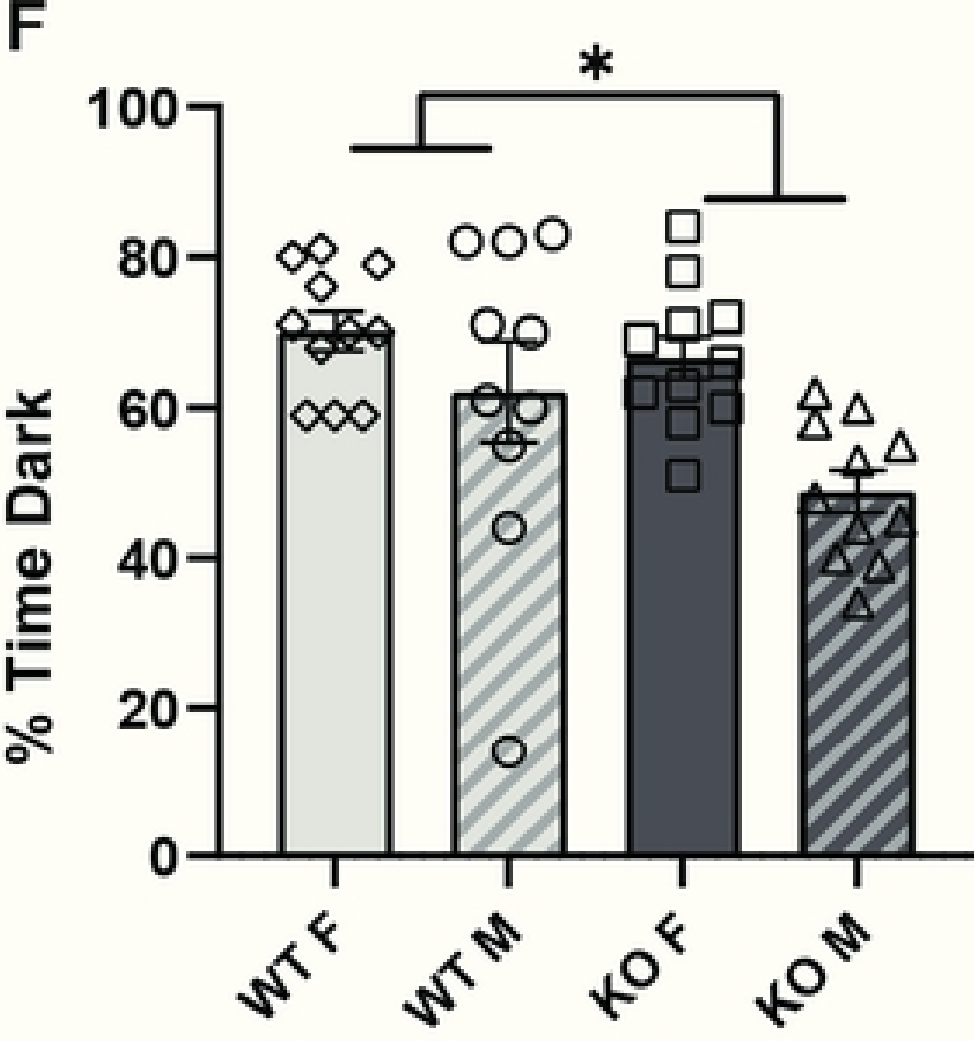

Figure 3 

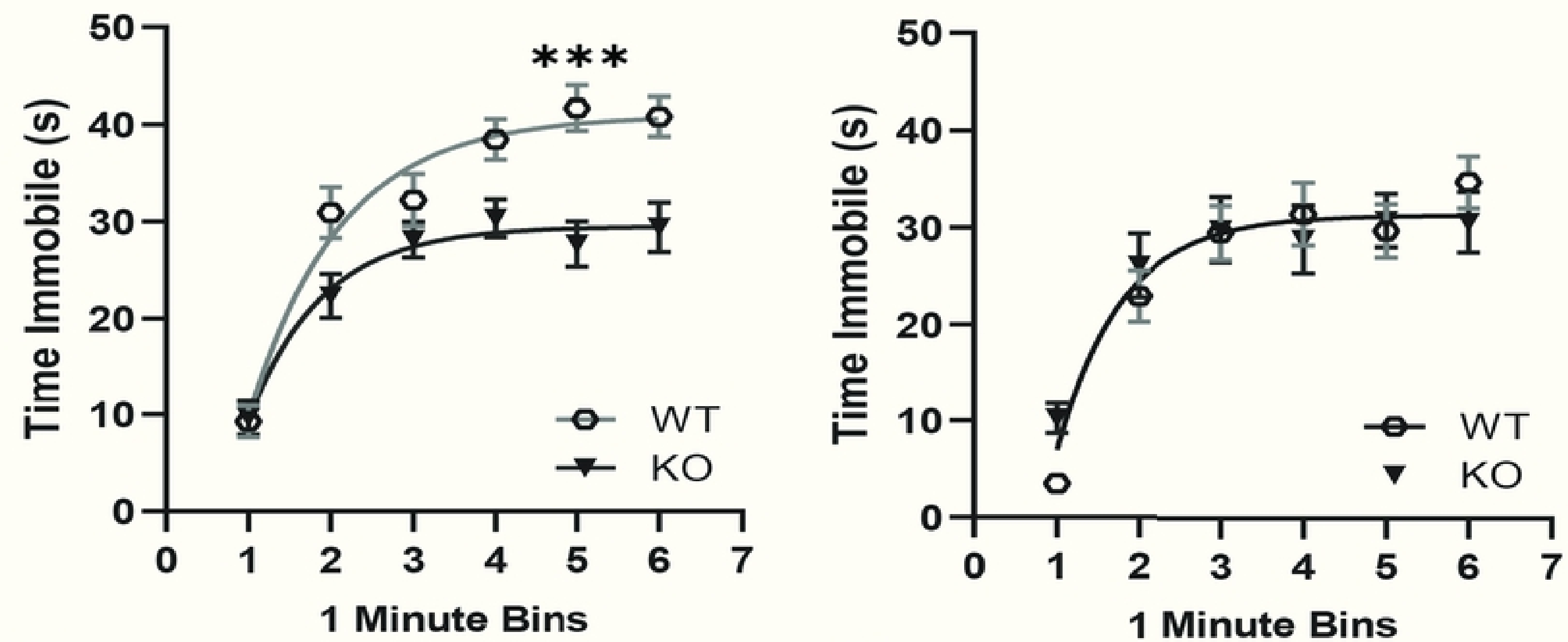

B E

E
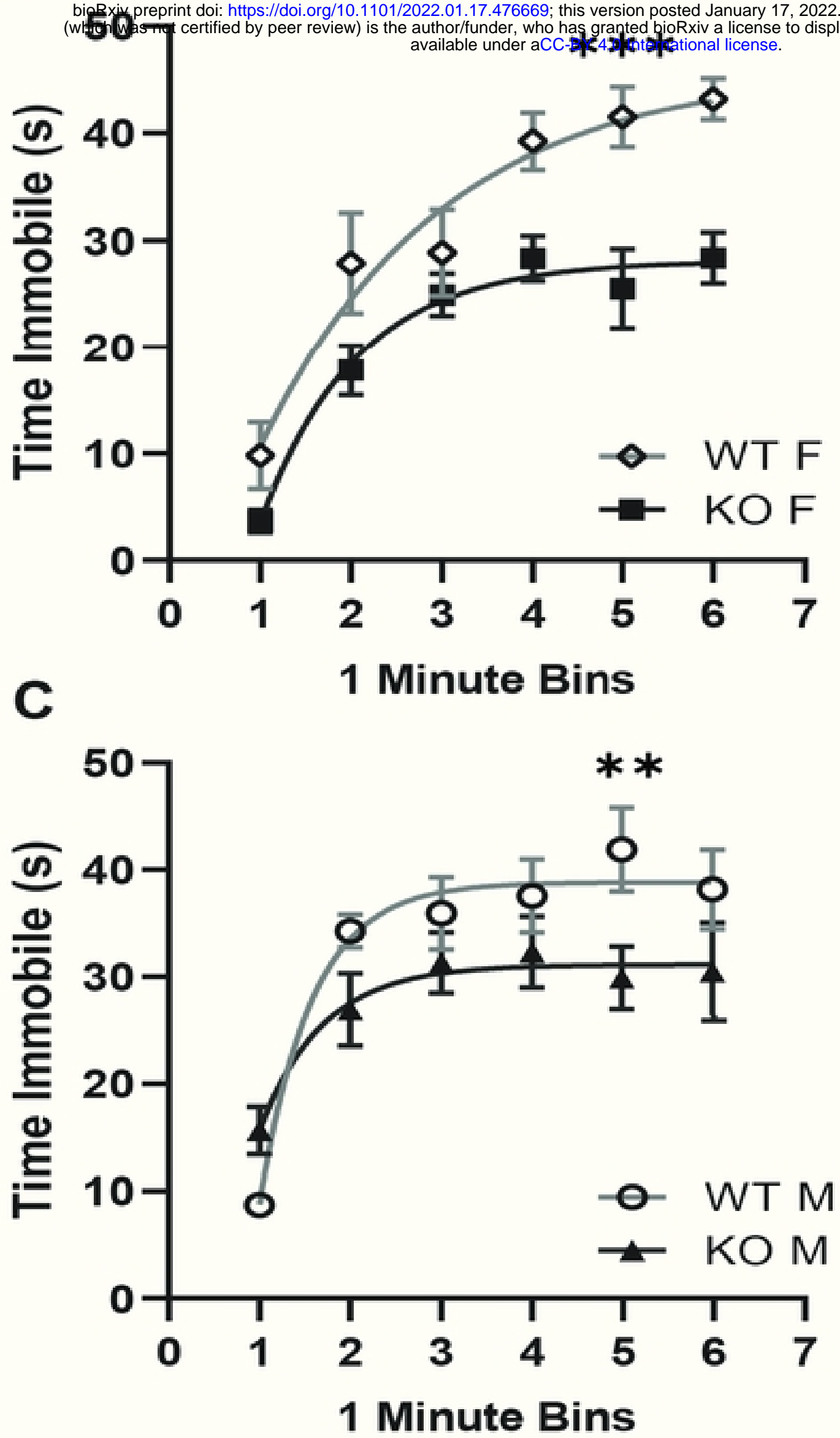

$\mathbf{F}$
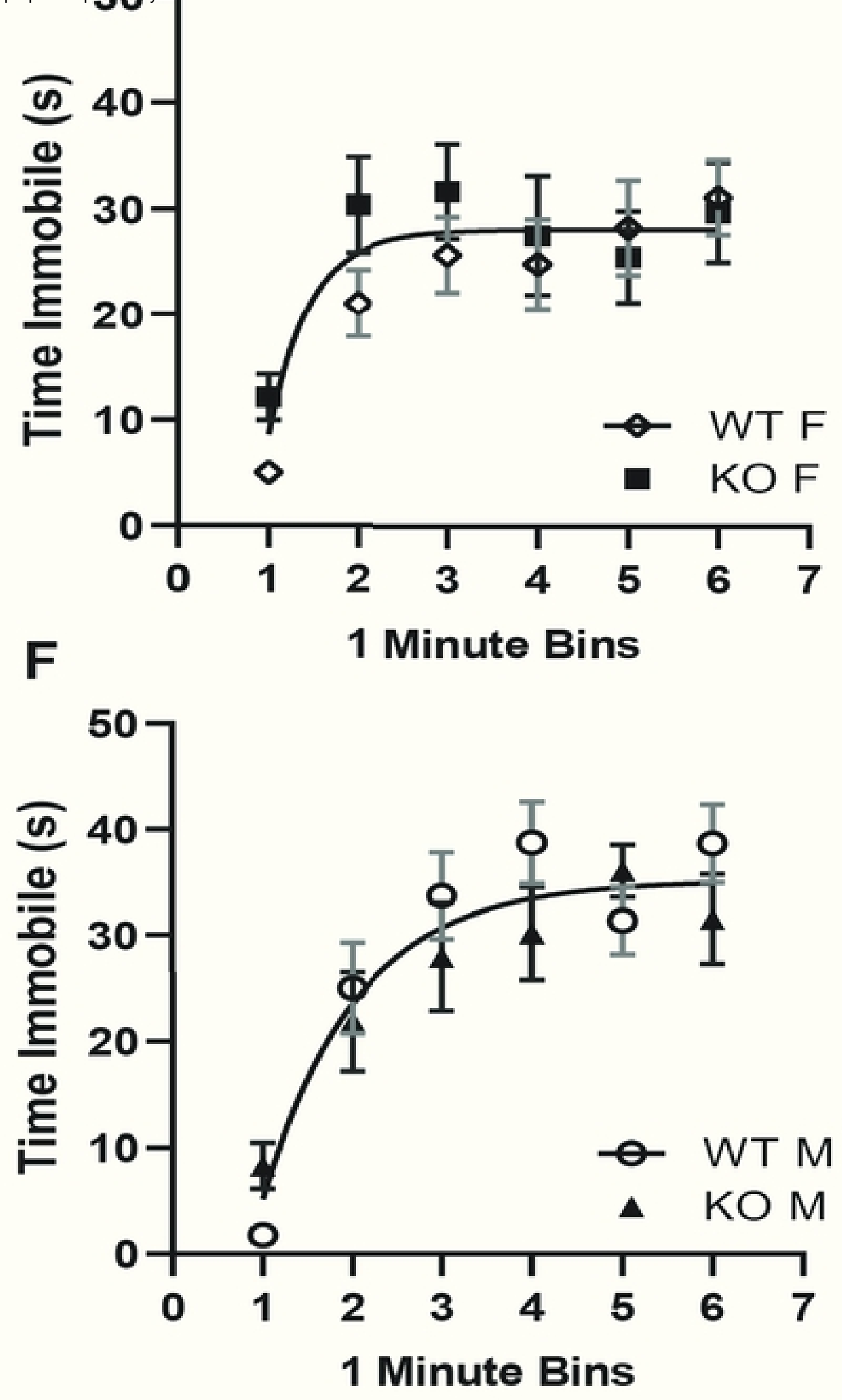

Figure 4 
Figure 5
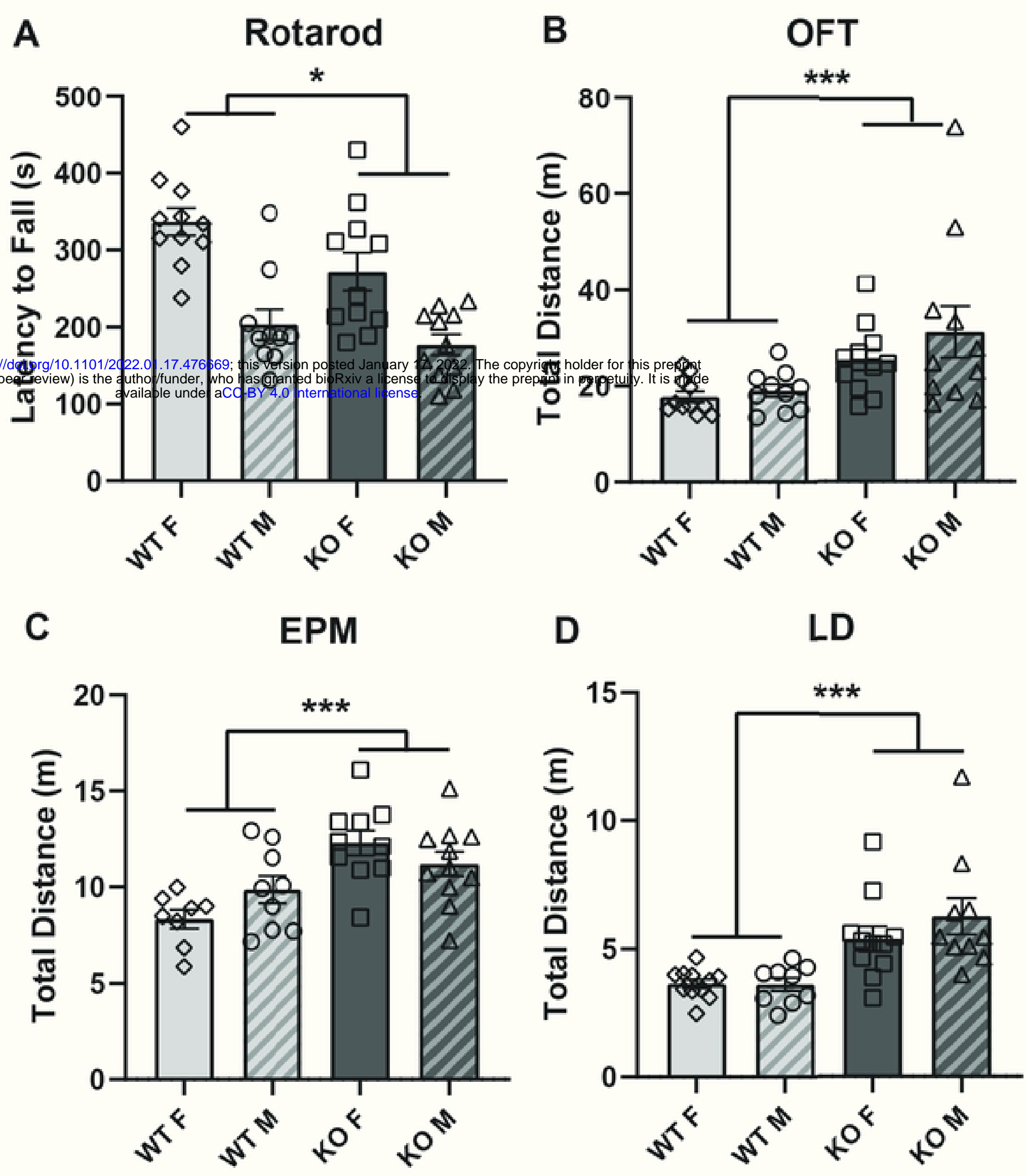

Figure 5 